\title{
Coffee's Dark Secrets: Linguistic Variation in Starbucks and Dunkin Donuts
}

by Lilah Butler

\section{Introduction}

Coffee shops have a rich linguistic and social history, particularly as displays of class and style. Modern sociolinguistic analyses of coffee shops, such as Paul Gaudio's "Coffeetalk," reference coffee's colonial past; in Europe, coffee became firmly established "among the trend-setting strata" of society by approximately 1700 , having been imported from the Islamic world (Schivelbusch, 1992, p. 19). For Europe's court aristocracy, coffee became "one more flourish to its cult of luxury," determined not by coffee itself "but how it could be consumed, the opportunities it afforded for display of elegance, grace, and high refinement" (Schivelbusch, 1992, p. 19). On the other hand, "bourgeois society of the same period regarded coffee in a different, quite contrary light" focusing on its function rather than the role of coffee in performing status (Schivelbusch, 1992, p. 19). The social distinction between coffee as display and coffee as a mere source of caffeine continues today, appearing in the linguistic distinctions of two different coffee shop chains, Dunkin Donuts and Starbucks. The issue of differentiation based on socio-economic class in such ubiquitous and quotidian locations as coffee shops is relevant to society at large because of the related issues of class, race, and gender based segregation. Considering the role of linguistics as a proxy for class, race, ethnicity, and gender, the study of the sociolinguistic elements of coffee shops relates to more obvious divisions in the United States as well as fields such as marketing and the importation of goods.

Historically, coffee shops have functioned as a public space, essential for spreading the news of the day (Schivelbusch, 1992, p. 51). They often claimed a romanticized role as forums of democracy, a place where noblemen and day laborers could socialize indiscriminately (Gaudio, 2003, p. 670). However, Gaudio (2003) argues that this vision is somewhat false, as these coffeehouses often barred women and hosted a sophisticated clientele that often shared literature, passing along personal, political, and cultural news, thereby gradually intertwining the "sphere of public opinion" and the "sphere of traditional authority" (p. 672). This supposed openness masking segregation continues - as Gaudio quotes from a Hispanic teenager, in the modern US, "Coffee is for white girls" (Gaudio, 2003, p. 684).This quote supports Gaudio's argument that the concept of "going out 
to coffee" in American culture seems unremarkable but is instead culturally and historically significant, based on class, race, geography, capitalism, and colonialism. Gaudio describes the coffeehouse experience epitomized in Starbucks as targeted to a cosmopolitan, cultured middle-class clientele, especially women. Examples of Starbucks locations in expensive, majoritywhite neighborhoods provide evidence for the economic, racial, and geographic constraint of "Coffeetalk" in Gaudio's paper. Gaudio's term "Coffeetalk" refers to the cultural phenomenon of commercialized casual conversation, stating that these supposedly ordinary conversations taking place in coffee shops "are inextricably implicated in the political, economic, and cultural-ideological processes of global capitalism, as symbolized by the increasingly ubiquitous Starbucks coffee company" (Gaudio, 2003, p. 659).

Another article by Manning (2008), also discusses Starbucks, taking a conversational-analysis based approach. Manning argues that baristacustomer interactions at Starbucks are "imagined implicitly as being different from those at Tim Hortons or Dunkin Donuts" (p. 117). Starbucks, unlike these other examples, employs a "relatively standardized and branded lexicon," depending on the "idea that customers do not just want coffee, they want distinction" (Manning, 2008, p. 106). This distinction manifests in the difference between using the Starbucks-specific lexicon, in correct order and with correct abbreviations, and using both the syntax and vocabulary that one might use unhesitatingly at a Tim Hortons but would be considered incorrect at Starbucks (Manning, 2008, p. 106). Consequently, "customer class anxiety is foregrounded in a Starbucks service encounter to an extent we would never find in a Canadian Tim Hortons or its American equivalent, Dunkin Donuts" (Manning, 2008, p. 106). In short, the unique Starbucks lexicon is inextricably linked to class and position.

Manning and Gaudio's work provides evidence for two clear phenomena: first, Starbucks provides its own distinct lexicon from Dunkin Donuts. Second, Starbucks aims to create more of an experience, rather than merely a beverage, and also intends to market to the upper and middle classes, or at least those desiring to be in those classes. How does that experience differ from that of Dunkin Donuts, and what language creates that distinct experience of Starbucks? My research seeks to answer those questions. My hypothesis argues that Starbucks and Dunkin Donuts use language differently, as Starbucks provides specific coffee-related jargon with the goal of distinguishing itself from other coffee shops, whereas Dunkin Donuts uses what one might call the "normal" language of most coffee shops and thereby avoids both the advantages and the dangers of a specialized, brand-specific lexicon. 


\section{Method}

\subsection{Participants}

I interviewed two baristas from Starbucks and two from Dunkin Donuts, at separate Starbucks and Dunkin Donuts locations. They were recruited randomly based on which barista was at the counter when I walked in, as there were always one to three other baristas in the shop at the same time. I asked each barista that I spoke with explicitly if they would mind being interviewed, and all were very polite in agreeing. I interviewed one barista at the Dunkin Donuts on Commonwealth Avenue across from St. Ignatius Church, one at the Dunkin Donuts in Cleveland Circle next to the Reservoir T stop, one barista at the Starbucks in Newton Center, and one barista at the Starbucks in Cleveland Circle, right across the street from the Dunkin Donuts there. All locations are about a mile and a half away from campus (the Dunkin Donuts on Commonwealth Avenue is an exception and much closer), with the goal of controlling for dialectical differences as well as the differences in the racial, socio-economic, and age composition of distinct areas around Boston. In an attempt to outsmart the observer's paradox, I truthfully explained that my research was for a class, but I did not mention linguistics, instead saying vaguely that I was studying different marketing techniques in coffee shops. Although four is a small sample size, given the continuity in both employee training and the interviews themselves these four interviews provide sufficient data for this project. The consistency between baristas of the same company helps demonstrate that my results hold true throughout the company instead of merely occurring at one particular store (examples of the consistency appear in the discussion and interview records). I did not ask the baristas for demographic information or recruit on the basis of macro-level factors; although I considered attempting to analyze the demographics of clientele and employees in various shops, I decided it was more ethical to omit that information from my analysis and appendix.

\subsection{Materials}

For my interviews with baristas, I attempted to use the same script in each instance. However, some variability occurred due to context - for example, if I began with "excuse me" or "hi," depending on what the baristas was doing. Another instance of necessary variability occurred in that a few times a customer approached the counter and I told the barista I was interviewing that I could wait while they helped another customer. Beyond these minor variations, here is my script, in order:

1) Excuse me, do you have a second? I have kind of a strange question - I'm working on a project about marketing in 
different coffee shops. Would it be okay if I ask you just a few questions?

This question merely served as context.

2) What's your favorite drink here?

This question functioned to reassure the baristas that this would be a casual interaction as well as to solicit both coffee-related jargon and the baristas' own honest opinions of the locations in which they worked.

3) How are you taught to greet customers?

I thought this question would help inform me how much of customerbarista interactions were prescribed by the company and how much was individual choice.

4) Are there things you are not allowed to say to customers?

Similarly, I wanted to learn more about how companies dictated the language used with customers from the upper levels of management down.

5) If/when customers become upset with you, how are you supposed to deal with that and what are they usually upset about?

This question focused more on general attitude towards customers as opposed to specific linguistic choices. I hoped to understand how baristas were trained to approach customers overall.

6) What's your dark roast like?

I added this last question as a further attempt to solicit coffee-related jargon after my first question failed to elicit as much detail as I would have liked. Consequently, my first interview lacked this question.

\subsection{Procedure}

In performing this research, I entered either a Starbucks or a Dunkin Donuts and ordered a drink, then positioned myself at a table near the register. Next, I listened to interactions between customers and baristas at both Dunkin Donuts and Starbucks and noted the first word or phrases used to initiate conversation. I attempted to use every interaction, although a few were inaudible and consequently omitted from my data. Overall, I recorded the initial words or sentences in 108 interactions. I recorded observations at midday, between the hours of $11 \mathrm{am}$ and $1 \mathrm{pm}$, in both locations in an attempt to control somewhat for variations in language depending on time 
of day; whenever I visited the stores in the evening I interviewed baristas instead because customer traffic was slow. I wrote down this data instead of recording it electronically for ethical reasons. Furthermore, I copied down the posted menus for both stores and interviewed baristas from both Starbucks and Dunkin Donuts. Other than ordering and my interview, I did not communicate with the baristas, so they almost certainly were not selfconscious in interacting with customers, as I attempted to be as unobtrusive and subtle as possible. Consequently, the customers waited in line, ordered, and waited for their drinks as they normally would, without consideration given to me.

\section{Results}

Table 1: Data - Conversation Initiation

\begin{tabular}{|c|c|c|c|}
\hline & Greeting & $\begin{array}{l}\text { Number of Instances, } \\
\text { Starbucks Cleveland } \\
\text { Circle }\end{array}$ & $\begin{array}{l}\text { Number of Instances, } \\
\text { Dunkin Donuts, } \\
\text { Commonwealth Avenue }\end{array}$ \\
\hline 1 & Hi, what can I get for you? & $\operatorname{xxxxxxxxxxxxxxxx(16)}$ & \\
\hline 2 & $\begin{array}{l}\text { How're ya doing? ('re is } \\
\text { basically swallowed) }\end{array}$ & $\operatorname{xxxx}(4)$ & \\
\hline 3 & $\begin{array}{l}\text { Can I get something started } \\
\text { for you, miss? }\end{array}$ & $x x(2)$ & \\
\hline 4 & $\begin{array}{l}\text { What can I get going for } \\
\text { you today? }\end{array}$ & $\mathrm{xx}(2)$ & \\
\hline 5 & $\mathrm{Hi}$ & $\operatorname{xxxxxxxxxxxxx(13)}$ & xxxxxxxxxxxxxxxx (16) \\
\hline 6 & Hey & $\mathrm{x}(1)$ & \\
\hline 7 & How're you doing today? & $\mathrm{xx}(2)$ & \\
\hline 8 & Morning & $\mathrm{x}(1)$ & \\
\hline 9 & $\begin{array}{l}\text { Hi, what can I get started } \\
\text { for you? }\end{array}$ & $\mathrm{xx}(2)$ & \\
\hline 10 & What can I get for you? & $\mathrm{xxx}(3)$ & \\
\hline 11 & $\begin{array}{l}\text { Hi, can I get a drink started } \\
\text { for you? }\end{array}$ & $\mathrm{x}(1)$ & \\
\hline 12 & $\begin{array}{l}\text { Can I get a drink started for } \\
\text { you? }\end{array}$ & Xxxxxxxxxxxxxxx (15) & \\
\hline 13 & $\begin{array}{l}\text { *Expectant questioning } \\
\text { look* }^{*}\end{array}$ & $\mathrm{xx}(2)$ & \\
\hline 14 & $\begin{array}{l}\text { What can I get started for } \\
\text { you? }\end{array}$ & $\mathrm{x}(1)$ & \\
\hline 15 & $\begin{array}{l}\text { Hi, what did we get for } \\
\text { you? } \\
\text { (used by barista ringing up } \\
\text { when the other barista has } \\
\text { already started a drink) }\end{array}$ & $\mathrm{x}(1)$ & \\
\hline 16 & Hi, how're you doing? & $x(1)$ & \\
\hline
\end{tabular}




\begin{tabular}{|c|c|c|c|}
\hline 17 & Hi, how's it going? & $\mathrm{x}(1)$ & \\
\hline 18 & $\begin{array}{l}\text { What's going on, how ya } \\
\text { doing? }\end{array}$ & $\mathrm{x}(1)$ & \\
\hline 19 & What's up? & $\mathrm{x}(1)$ & \\
\hline 20 & Hello, how ya doing? & $\mathrm{xx}(2)$ & \\
\hline 21 & $\begin{array}{l}\text { Hello, how's it going } \\
\text { today? }\end{array}$ & $\mathrm{x}(1)$ & \\
\hline 22 & $\begin{array}{l}\text { How ya doing, how are } \\
\text { you guys? }\end{array}$ & $\mathrm{x}(1)$ & \\
\hline 23 & Hello & & $\mathrm{x}(1)$ \\
\hline 24 & $\begin{array}{l}\text { Can I help who's next } \\
\text { please? }\end{array}$ & & $\mathrm{x}(1)$ \\
\hline 25 & Hi, how can I help you? & & $\mathrm{xx}(2)$ \\
\hline 26 & What can I get for you? & & $\mathrm{x}(1)$ \\
\hline 27 & Hi, how are you? & & Xxxxxxxxxx (10) \\
\hline 28 & $\begin{array}{l}\text { Customer - How's it } \\
\text { going? }\end{array}$ & $\mathrm{x}(1)$ & \\
\hline 29 & Customer - Hi & $\mathrm{xx}(2)$ & \\
\hline 30 & Total & 77 & 31 \\
\hline
\end{tabular}

Table 2: Conversation Initiation by Category

\begin{tabular}{|c|c|c|c|c|c|}
\hline & Category & $\begin{array}{l}\text { Number of } \\
\text { Instances, } \\
\text { Starbucks } \\
\text { Cleveland } \\
\text { Circle }\end{array}$ & $\begin{array}{l}\text { Percentage, } \\
\text { Starbucks }\end{array}$ & $\begin{array}{l}\text { Number of } \\
\text { Instances, Dunkin } \\
\text { Donuts } \\
\text { Commonwealth } \\
\text { Avenue }\end{array}$ & $\begin{array}{l}\text { Percentage, } \\
\text { Dunkin } \\
\text { Donuts }\end{array}$ \\
\hline 1 & $\begin{array}{l}\text { Single-word } \\
\text { greeting - Hi, } \\
\text { Hey, Morning, } \\
\text { Hello }\end{array}$ & 15 & $20 \%$ & 17 & $55 \%$ \\
\hline 2 & $\begin{array}{l}\text { Customer } \\
\text { initiated - Hi, } \\
\text { Hello }\end{array}$ & 3 & $4 \%$ & 0 & $0 \%$ \\
\hline 3 & $\begin{array}{l}\text { Greeting and } \\
\text { question } \\
\text { regarding } \\
\text { ordering- Hi, } \\
\text { how can I help } \\
\text { you? Hi, can I } \\
\text { get a drink } \\
\text { started for you? } \\
\mathrm{Hi} \text {, what can I } \\
\text { get started for } \\
\text { you? Hi, what } \\
\text { can I get for } \\
\text { you? }\end{array}$ & 20 & $26 \%$ & 2 & $6 \%$ \\
\hline 4 & $\begin{array}{l}\text { Greeting and } \\
\text { phatic question } \\
-\mathrm{Hi} \text {, how are } \\
\text { you? Hi, how } \\
\text { are you doing? }\end{array}$ & 5 & $6 \%$ & 10 & $32 \%$ \\
\hline
\end{tabular}




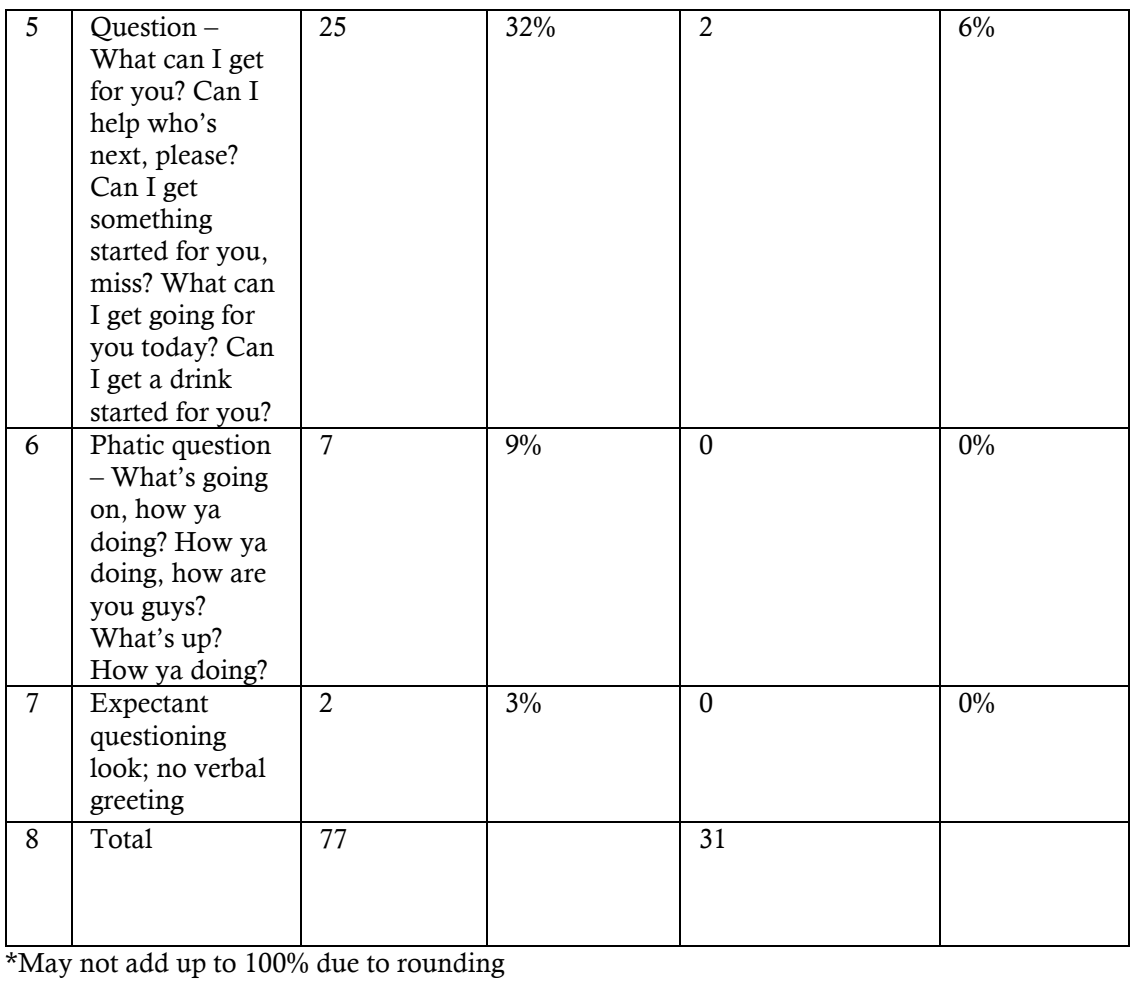

As Table 2 shows, baristas at Dunkin Donuts tended to initiate interactions with customers through a single world greeting such as "Hello" or "Hi." At Dunkin Donuts, $55 \%$ of interactions began this way whereas only $20 \%$ of interactions at Starbucks commenced with a single-word greeting. Dunkin Donuts baristas also used a single-word greeting combined with a phatic question more frequently than Starbucks, $32 \%$ of the time as opposed to $6 \%$. Starbucks baristas, on the other hand, were much more likely to use a question such as "What can I get for you?," which occurred in $32 \%$ of Starbucks transactions and 6\% of Dunkin Donuts transactions. Starbucks baristas also used greetings combined with questions regarding ordering (as opposed to phatic questions) more often than at Dunkin Donuts. Overall, Dunkin Donuts conversations generally began with regards to the customer, whereas Starbucks interactions usually focused more on the order itself. Because Dunkin Donuts and Starbucks showed such difference in focusing on greetings or questions relating to the order, I differentiated between sections three and five rather than combining them, because doing so emphasizes that Starbucks baristas were more likely to jump right into a phrase directly related to the order than greet customers first and then focus on ordering.

Interviews with baristas also demonstrate a much greater range of coffeerelated jargon at Starbucks than at Dunkin Donuts. Furthermore, Starbucks baristas received much more explicit inscription on language to use with customers, such as avoiding saying the word "no" or the phrase "you're 
welcome," as they are supposed to say thank you instead (lines 22, 64 in Records of Barista Interviews, located in the Appendix; hereafter cited simply by line number). Dunkin Donuts, on the other hand, emphasizes general politeness but does not provide such a distinct lexicon.

\section{Discussion}

As Rose and Lily, baristas at Starbucks (names changed for privacy), pointed out, the specific lexicon of Starbucks presents the danger of customers feeling corrected (30-35). The value of this Starbucks-talk is distinction, setting Starbucks apart from other coffee shops, as Rose explains and authors like Manning corroborate (46-7; Manning, 2008 p. 107-8). The vocabulary required at Starbucks, then, provides a feeling of being "exclusive," with the corresponding compliment to those included and the alienation of those who do not control this specific code of Starbucks-talk; Manning explains that "while successful reference is enough to get served, it is not enough to lay claim to the prestigious properties of the object one is about to consume" (Manning, 2008, p. 105). As Lily mentioned, customers can view this lexicon as pretentious instead of desirable (30-35). On the other hand, Dunkin Donuts lacks company-specific words as well as instructions on what words are discouraged from customer-barista interactions. Starbucks baristas avoid saying "no" and "you're welcome;" Dunkin Donuts baristas appeared puzzled when I asked if there was anything they were not allowed to say to customers $(22,64,223-5,241-4)$. At Starbucks, baristas are told to thank the customers, instead of accepting customer thanks. Such a difference implies that Starbucks prioritizes having its own brand-specific language whereas Dunkin Donuts does not.

Rose and Lily's comments on the assumed wealth of Starbucks customers and the pretentiousness of Starbucks as compared with Dunkin Donuts support Gaudio and Manning's arguments that Starbucks markets to those wishing for a high-brow experience that, regardless of their actual socioeconomic class, makes them feel like members of a cultured elite $(140,46-$ 53). The baristas even stated emphatically (with obvious bias) the superiority of Starbucks coffee itself over Dunkin Donuts (46-53). Specifically, the Starbucks menu appeals to the idea of a cultured connoisseur by emphasizing the exoticism of coffee, as evidenced by sign six of the Starbucks menu in the appendix, which includes the specific names of growing countries and uses specific words and phrases usually reminiscent of high quality food and fine-dining, such as "allspice" and "balsam aroma." Quotes like "similar to wine, you can pick up on different notes as well" and "each region produces a kind of different flavor in their coffee beans" demonstrate Starbucks's desire to assert itself as superior and ideal for any real, sophisticated coffee lover $(112-3,213)$. When I asked baristas about their dark roast varieties, Dunkin Donuts baristas provided me with no 
information whereas Starbucks baristas gave long speeches explaining the different regions where their dark roasts grow and the associated characteristics $(250,258)$. Notably, the Starbucks baristas were genuinely knowledgeable and could tell me details about their coffee, while Dunkin Donuts employees were universally puzzled when I asked about their dark roast. Thus, Starbucks uses coffee-related jargon to distinguish itself as exclusive and sophisticated. Manning agrees, stating, "the vocabulary field of affordable luxuries such as coffee has taken on some of the statusindexing qualities associated with the vocabulary field of pricier prestige commodities, like wine or olive oil" (Manning, 2008, p. 105). Dunkin Donuts does not use the same breadth of coffee-related jargon, although clearly that does not indicate a lack of financial success or expansion. Instead, Dunkin Donuts appears to operate on a model of polite, unassuming simplicity, providing coffee, certainly with some variety, such as the "caramel swirl cream iced coffee" (217), but without the exotic appeals or aura of high class culture of Starbucks.

Regarding conversation initiation, the brief phatic greetings used more frequently at Dunkin Donuts and questions used at Starbucks corresponds with the evidence provided regarding training and allowed words, again implying that Starbucks deliberately uses language to entice customers through an aura of upper-class sophistication. Given an expensive, upperclass establishment compared with a more lower-class based company, one would expect the store marketing to higher socio-economic classes to use questions, expressing deference and helpfulness, more frequently than brief, informal greetings like "hi." The higher level of customer service is likely more consistent with Starbucks's target audience, then. Consequently, this data supports Gaudio and Manning's claims that Starbucks, unlike Dunkin Donuts, attempts to distinguish itself through language use, thereby appealing to customers wishing for a cultured, upper-class experience. Furthermore, as Starbucks baristas use questions about the order more often while Dunkin Donuts baristas use phatic questions more frequently, Starbucks focuses the customer's attention on the coffee itself, as well as the associated experience of ordering a complicated drink. It may seem absurd to describe Starbucks as elite, but both authors emphasize that Starbucks does not exclusively market to upper-class individuals; instead, it markets to those wishing to act like upper-class individuals. The same phenomenon occurs in the menus, with the Starbucks menu containing elaborate, multiword drink names as well as many holiday beverages. The Dunkin Donuts menu involves simpler, shorter names, fewer trademarked or distinctly Dunkin Donuts drinks, and a large variety of food options. Regarding outof-the-ordinary drinks Dunkin Donuts has a "Frozen Dunkin' Coffee" and Almond Joy or Dunaccino hot chocolate, whereas Starbucks has Frappuccinos, Refreshers, and ten or so seasonal, winter-themed concoctions like the "Chestnut Praline Chai Tea Latte." These holiday drinks use words with great sensory appeal, particularly given the repeated 
references to spice and the associated scents. Returning to the ideas of function versus appearance and class-based appeal in the introduction, the usefulness of food and coffee appears on display in Dunkin Donuts, whereas Starbucks highlights colorful holiday drinks and elaborate coffee beverages from an exotic locale.

Finally, even the names of the coffee shops correspond with the associations of their menus, greetings, and barista comments. Dunkin Donuts clearly uses the -in' variant in its name as opposed to -ing, generally considered the standard. Michael Huspek (1986) in Language in Society explains that for North American workers -in' is a low prestige variant (p. 149).

Consequently, "Dunkin Donuts" as a name, and correspondingly as a company, prioritizes solidarity over prestige. Starbucks, on the other hand, derives its name from the character Melville's first mate, Starbuck, in Moby Dick (Allison, 2008). The founders wanted to use a name beginning with "st" because of advice that such words are "powerful" (Allison, 2008). Starbucks, then, chose a highbrow literary reference as well as a sense of power as opposed to choosing a covert prestige variant like Dunkin Donuts. Thus, even the names of the two coffee shops promote distinction, a wellread connotation for Starbucks and a sense of solidarity for Dunkin Donuts.

Overall, evidence from menus, barista interviews, and customer-barista interactions supports my hypothesis that Starbucks and Dunkin Donuts use language differently, with Starbucks attempting to distinguish itself through coffee-related jargon and interactions between baristas and customers, whereas Dunkin Donuts uses a more standard, even solidarity-based approach.

\section{Conclusion}

In conclusion, my research corroborates the work of Manning and Gaudio, who argue that Starbucks has its own standardized lexicon which contributes to a sense of upper-class exclusivity, a lexicon that Dunkin Donuts lacks. This study contributes to the intersection of marketing and linguistics as well as sociological analysis on why, despite a lack of overt rules, certain races, genders, and ethnicities frequent certain locations while avoiding others. In hindsight, I would have liked to control more for individual variations in barista greetings by gathering more data at a larger variety of locations across the city, but of course, given time constraints, that was not realistic. Additionally, recording these interviews as opposed to writing down their responses would have likely provided more accuracy, but it also would have increased their self-consciousness. Regardless, my barista interviews were startling similar between baristas of the same company, suggesting that my small sample size accurately sampled both companies' employees. For instance, both baristas at the two chains responded very 
similarly to the question about dark roasts, and both Starbucks baristas mentioned the apron model of behavior while the Dunkin Donuts baristas referenced smiling $(103,203,221,240)$. Coffee and coffee shops reveal a treasure trove of future studies. For example, Gaudio (2003) points out the wealth of social rules regarding meeting for coffee, so further research could certainly focus on what topics are allowed and what topics taboo in coffee shops and why people meet for coffee as opposed to merely chatting in a home. Furthermore, the idea of correction of customers by baristas, which Manning discusses in his article and baristas mentioned in interviews with me, would be interesting to further investigate in Starbucks locations (30-35). Finally, this study could be replicated internationally to determine how translation affects the split between Starbucks and other coffee shops. Future studies could also survey more coffee shops than just Starbucks and Dunkin Donuts, particularly regarding independent as opposed to chain coffee shops. Ideally a future study would also include information on pricing and provide analysis on how prices correlate with language use in various different coffee shops. 


\section{REFERENCES}

Allison, Melissa. (2008, March 9). Starbucks co-founder talks about early days, launching Redhook and Seattle Weekly, too. The Seattle Times. Retrieved from

old.seattletimes.com/html/businesstechnology/2004269831_bowker09.htm 1.

Gaudio, Rudolf P. (2003). Coffeetalk: Starbucks and the commercialization of casual conversation. Language in Society, 32(5), 659-691.

Huspek, M. (1986). Linguistic variation, context, and meaning: A case of ing/in' variation in North American workers' speech. Language in Society, 15(02), 149-163.

Manning, P. (2008). Barista rants about stupid customers at Starbucks: What imaginary conversations can teach us about real ones. Language and Communication, 28(2), 101-126.

Peiper, Heidi. Congo coffee takes center stage as latest exclusive roastery beverage. Starbucks Newsroom. Retrieved from news.starbucks.com/news/congo-coffee-star-of-latest-exclusiveroastery-beverage.

Schivelbusch, Wolfgang (1992). Tastes of Paradise: A Social History of Spices, Stimulants, and Intoxicants. (David Jacobson, Trans.) New York, NY: Random House. (Original work published 1980) 


\section{APPENDIX}

Menus and Signage 1: Starbucks

Prices and calories omitted for brevity, numbered to clarify distinctions between separate signs; there were six signs in total. My clarifications are in italics and brackets.

(1)

SEASONAL CHEER

ESPRESSO \& TEAVANA ${ }^{\circledR}$ TEA tall $12 \mathrm{fl} \mathrm{oz}$ grande $16 \mathrm{fl} \mathrm{oz}$

cal venti $20 / 24 \mathrm{fl} \mathrm{oz} \mathrm{cal}$

Toasted White Chocolate Mocha

Chestnut Praline Latte

Caramel Brulée Latte

Peppermint Mocha

Eggnog Latte

Gingerbread Latte

Pumpkin Spice Latte

Salted Caramel Mocha

Holiday Spice Flat White

Chestnut Praline Chai Tea Latte

Frappuccino ${ }^{\circledR}$ Blended Beverages

Toasted White Chocolate Mocha

Peppermint Mocha

Caramel Brulée

\section{Customize Any Drink}

- $\quad$ Flavor $+50+0-25$ cal per pump

- $\quad$ Espresso Shot $+80+5 \mathrm{cal}$

- Venti Iced up to 30 cents

- Sumatra Coconutmilk, Organic Soymilk or Almondmilk +60c

(2)

CLASSIC JOY

ESPRESSO, COFFEE, \& MORE

Flat White

Caffè Latte

Caffè Americano

Caramel Macchiato

White Chocolate Mocha

Freshly Brewed Coffee

Nariño 70 Cold Brew

Vanilla Sweet Cream Cold Brew

Hot Chocolate

Frappuccino ${ }^{\circledR}$ Blended Beverages

Caramel

Mocha

Teavana Tea \& Starbucks Refreshers

Iced Tea Infusions Lemonades

Classic Chai Tea Latte

Strawberry Açai (contains caffeine) 
We cannot guarantee that any of our products are free from allergens (including dairy, eggs, soy, tree nuts, peanuts, wheat, and others) as we use shared equipment to store, prepare, and sere them. Before placing your order, please inform your server if a person in your party has a food allergy.

(3)

Flat White

Holiday Spice Flat White,

[With pictures of all]

(4)

FESTIVE HOT COCOA

NEW TOFFEE ALMONDMILK HOT COCOA

PEPPERMINT HOT COCOA

SNICKERDOODLE HOT COCOA

SALTED CARAMEL HOT COCOA

[With pictures of all]

(4)

Good Delights:

Peppermint Mocha

NEW Toasted White Chocolate Mocha

Caramel Brulée Latte

[with pictures of all three]

(5)

NOW HIRING:

- COMPLIMENTARY FOOD \& DRINKS!

- COLLEGE ACHIEVEMENT PLAN!

- $401(\mathrm{~K}) \&$ STOCK OPTIONS!

- INSURANCE COVERAGE!

- STORE DISOUNTS!

- FLEXIBLE HOURS!

- FREE SPOTIFY!

OPPORTUNITY is BREWING

CONTACT MATTHEW FOR ADDITIONAL INFORMATION!

(6)

Starbucks Reserve Coffee

Our proprietary clover brewing system reveals vibrant layers of aroma and flavor in each STARBUCKS RESERVE COFFEEE.

Reserve

Aged Sumatra

Tall

3.50 Grande 4.00

Christmas Reserve

Sorry, we're all out

Congo Kawa Kabuya

$3.00 \quad 3.50$

Etopia Bitta Farm

3.50

4.00 [presumably a

misspelled version of Ethiopia]

Nicaragua Marracaturra 4.00

4.50

Vietnam Da Zat

3.00

3.50 
[Four small square signs on the second half of this last chalkboard, with the names of some of these coffees on colorful backgrounds and short flavor descriptions, listed below]

Aged Sumatra, Grow year 2013, Small-Lot Coffee - Balsam Aroma \& Earthy D.R. Congo Kawa Kabuya, Small-Lot Coffee - Hibiscus \& Lemon Ethiopia Bitta Farm Small-Lot Coffee - Banana \& Chocolate Nicaragua Maracaturra Small-Lot Coffee - Red Apple \& Allspice

Menus and Signage 2: Dunkin Donuts

[These are four electronic signs with pictures rotating through on the margins.]

(1)

coffee

SMALL MEDIUM LARGE

COFFEE

ESPRESSO

AMERICANO

LATTE

CAPPUCINO

MACCHIATO

ICED COFFEE

ORIGINAL BLEND, DARK ROAST

COLD BREW

SMALL BATCHES DAILY

ICED LATTE

ICED MACHIATO

FROZEN DUNKIN' COFFEE

ADD FLAVOR:

CARAMEL MOCHA FRENCH VANILLA HAZLENUT RASPBERRY

BLUEBERRY COCONUT TOASTED ALMOND

(2)

beverages SMALL MEDIUM LARGE

CIOCOLATTA

STRAWBERRY, VANILLA BEAN,

BLUE RASPBERRY

SMOOTHIE

STRAWBERRY BANANA

ICED TEA

BLACK, GREEN

TEA BLACK, GREEN

CAFFEINE FREE: CHAMOMILE, MINT

HIBISCUS

VANILLA CHAI

HOT CHOCOLATE

ORIGINAL, ALMOND JOY, DUNACCINO

HOT CHOCOLATE FROZEN

VANILLA CHAI FROZEN

DUNKIN ENERGY PUNCH

POWERED BY MONSTER ENERGY

[COCOA COLA, DIET COKE, SPRITE, AND SIMPLY ORANGE LOGOS AT

THE BOTTOM OF THE SCREEN] 
(3) all day choices

BIG N' TOASTED

2 EGGS, BACON \& CHEESE ON TEXAS TOAST

ANGUS STEAK

WITH EGG \& CHEESE ON A PLAIN BAGEL

SAUSAGE, EGG, \& CHEESE

ON A CROISSANT

BACON, EGG, AND CHEESE

ON A PLAIN BAGEL

TURKEY SAUSAGE, EGG, \& CHEESE

ON A FLATBREAD

CHICKEN SALAD

ON A CROISSANT

DELUXE GRILLED CHEESE

CHOICE OF HAM OR BACON

HAM \& CHEDDAR

ON A CIABATTA

HAM, EGG, \& CHEESE

ON AN ENGLISH MUFFIN

VEGGIE EGG WHITE

ON A FLATBREAD

WAKE-UP WRAP

SAUSAGE, BACON, TURKEY SAUSAGE, OR HAM

CHICKEN BACON

ON A CIABATTA ROLL

TURKEY, CHEDDAR BACON

ON A CIABATTA ROLL

2000 calories a day is used for general nutrition advice, but calorie needs

vary. Additional nutrition information available upon request

(4)

bakery

CLASSIC DONUT

FANCY

MUNCHKINS

BAGEL

W/O CR. CHEESE SPREAD

W/ CR. CHEESE SPREAD

CLASSIC PLAIN, REDUCED FAT PLAIN, GARDEN VEGGIE, STRAWBERRY

MUFFIN

CROISSANT

DANISH

snacks

CHICKEN

SNACK N' GO WRAP

HASH BROWNS

BAGEL TWIST

MULTIGRAIN BROWN SUGAR OATMEAL 


\section{Records of Barista Interviews:}

\section{Starbucks, Newton Center, 12/1/17}

Note: I was talking to the first barista, code-named Rose, but the second barista, "Lily," chimed in on multiple occasions (X) marks an interruption as barista walks away to grab something or take an order or talks to a customer.

- Interviewer: What's your favorite drink here?

a. Soy caramel macchiato (What does that even mean) it's a caramel macchiato but I make it with soy milk because the soy milk we use here is vanilla so it makes it a little sweeter

- Interviewer. How are you taught to greet customers?

a. Are we taught to greet customers? We actually this is really fun we have a panel up here that tells us what to say. No, we're supposed to welcome them to Starbucks so we can make a connection

b. Interviewer: Can you pause for a second so I can write that down?

c. Rose: Absolutely, no problem. [brief pause] So we're supposed to make a connection no matter what station we're at. Make that connection no matter what station you're at, we're supposed to make everyone feel like this is kind of their third place is what we call it.

- Interviewer: Are there things you are not allowed to say to customers?

a. No. [As in no the word, as opposed to answering in the negative to my question.]

b. Lily chimes in: No is definitely number one, never say no.

c. Rose to Lily, jokingly: Shut up, please stop talking.

d. Lily: Our Frappuccino machine is broken.

e. Rose: We're out of ice cream.

f. Lily: Our ice cream machine is broken.

[These comments are to each other, jokingly, not directed at me]

g. Rose, to me now: I don't think we're supposed to correct people when they say small, medium, or large. I'll go to other Starbucks and they'll do it. Or they'll like overemphasize the word, like if the customer orders a small they'll repeat back 'so that's a tall [emphasized by Rose] nonfat iced whatever.' It depends on the employee but most of us have the decency not to do that, like I'll just say small if they say small.

h. Lily: Before I started working at Starbucks I thought the terminology was super pretentious

i. Rose: I felt so bad today one of our customers apologized to me for saying small. I was like no, no, it's okay, it is a small. You're supposed to feel welcome here. How are they supposed to know the history of Starbucks? They don't care.

j. Me, to Lily: Do you think the terminology is less pretentious now that you work here or do you still think it's pretentious?

k. Lily: I feel like in some things it's really unnecessary. I don't mind for the drinks, it's more so the pastries. It's just a cinnamon roll! What's a night bun? Or an afternoon bun?

1. Rose: I think a lot of it is to try to give us our own thing. It's supposed to be our own thing. Lots of places have small, medium, and large.

m. Rose, to Lily: The most pretentious thing about Starbucks is when someone who came in and said I went to Dunkin Donuts this morning and we say why.

n. Lily, to Rose: I don't understand people who drink Dunkin and then come here and then go back to Dunkin. I would never go back to Dunkin. Their coffee tastes like watered down crap. Do you know that's the reason they made the blond? That's the reason, it tastes like Dunkin Donuts coffee.

o. Rose: A lot of customers don't know this and I forewarn them. They think dark roast has the most caffeine but it doesn't, it has the least.

- Interviewer: If/when customers become upset with you, how are you supposed to deal with that and what are they usually upset about?

a. Rose: Ummm ooh this is, ok. I would say the things they get upset about, we run our coffee on a schedule. We have this kind of guideline set up of when we brew our coffee, [takes down the chart from the wall and shows me] so like we stop brewing dark roast in the afternoons on weekdays so sometimes people come in at like 2 or 3 and we don't have the dark roast, like we still have the clover. I thought of something else we're not supposed to say. Not that we're not 
supposed to but they try to have us not say it. 'You're welcome.' They prefer we say thank you back. It caught me a little bit, yeah, so my manager was in two or so weeks I'd say 'Oh, you're so welcome' and he'd say no. It's hard, you know, it's just a reflex, people say 'thank you' and 'oh you're welcome.' Sometimes you get in a cycle of no, thank you, no thank you, thank you. We're supposed to be thanking them.

b. Rose to Lily: What makes customers upset?

c. Lily: We don't sell the breakfast sandwiches at this location

d. Rose: Umm, let me see if there's anything else. I would say other than that the only thing is when people order a drink that they don't like. we have a policy we remake any drinks that people don't like even if they just don't like what they ordered, so, shrugs.

e. Rose, to Lily: Is it the apron or latte model?

f. Rose, to me: Ok, we have this thing called the latte model. It's an acronym, I will do my best. We're supposed to apologize for the issue, see what actions we can take to correct it, fix the issue, and assure that it won't happen again. Yeah. We also have recovery cards, so if we miss something us, or if they have to wait say we're not brewing dark roast and I have to brew it on the clover and it takes longer, we can give them a card for like $\$ 4$ so the next time they come in their coffee is free.

g. Lily: Usually they'll tell us before hand to give out recovery cards

h. Interviewer: Ok, so what's clover?

i. Rose: The clover is this here machine. It's very good, Jerry approved [Jerry is a regular customer seated at the table behind me who has been chatting intermittently with Rose]. And the way we describe it is it kind of works like a reverse French press. So we measure it out, depending the size, whatever we weigh out goes through this grinder here and see there's like certain settings here for the size and type of coffee, and that gets added up here. Once the beans are added this part goes down, that thing once it's down it makes like this motion (moves hands together), it kind of vacuums it so the coffee's being sucked down out of it, so it leaves it with a very smooth flavor which I prefer, I don't know, I don't like coffee that's too thick, or acidic maybe. I've had medium or dark on the clover without milk or anything.

- Interviewer: What's the difference between a latte and a cappuccino?

a. Rose: A latte is just espresso and steamed milk and a cappuccino is half steamed milk half foam.

b. Lily: A cappuccino is topped with foam.

- Interviewer: What's your dark roast like?

a. Rose: Which one? [I make a confused, surprised face, she laughs]. So these right here are all dark roasts, the Christmas one we have a dark roast, and a clover one. the way I'm gonna answer this is I'll do the best I can. We have three different regions that we get our coffee from, the Pacific (X)

b. Rose, to Lily: So this is bad of me, but the three regions are the Pacific, some part of Africa right, and then Latin America.

c. Lily: I think it's SE Asia?

d. Rose: Yeah. So those are our three regions.

e. Interviewer: So it's Pacific, Africa, and Latin America? Or Southeast Asia?

f. Rose: Pacific, Africa, Latin America. The Pacific is like Southeast Asia usually. The reason that's relevant because each region produces a kind of different flavor in their coffee beans. Say the darks from Latin America will taste more citrus-y than the darks from the Pacific. And then the other thing that would be helpful is all of our bags on the sides of them have a description for typically where they're from and then it has a kind of individual. So like this is one dark roast and then another would be described kind of differently [Grabs two bags of dark roast beans and sets them in front of me]. So if you want to just, yeah.

g. Interviewer: oh, thank you

$\mathrm{h}$. While Rose and Lily both help customers, I record the descriptions on the sides of the bags of the two dark roasts (below).

i. Rose: You know what else is interesting? I don't know if it relates to your paper at all but I just think it's interesting. So, I would go to Starbucks all the time to do homework like before I worked here but now that I work here if I hear someone making drinks I'm like oh I have to go finish those drinks. So I don't do homework here anymore. Sometimes I'll go to Caffe Nerro or 
a Thinking Cup or something to do homework. I'll ask oh can you do this and they'll say no, this isn't Starbucks.

j. Lily: Starbucks is all sugar-y that's why, because they're trying to appeal to the kids.

k. Rose: I accidentally tried to order a grande and the person on register goes [glaring face; then Rose and Lily both laugh].

1. Lily: Was the thinking cup like oh we don't have that we're a real café.

m. Rose: Like macchiato is just a Starbucks thing they don't have that other places.

n. Lily: Also latte is on our menu and cappuccino is not for some reason.

o. Rose, to Lily: I asked Jerry if he would write a letter saying I can use the clover and he said he would.

p. Lily: You know what I should ask customers for? A job

q. Rose: A job, why?

r. Lily: A lot of them are hella rich.

Descriptions of the dark roast bags:

"The story of Komodo Dragon Blend:

Deep, untamed flavors ripple through. Earthy, herbal, and complex with a lingering spice. The scent is like as troll through the forest just after a rain. This is the essence of coffees from Indonesia, and no other beans bring these flavors. Our master coffee blenders have done something remarkable. Knitting together the best pieces of the region's coffees perfectly - allowing each taste to shine through clearly. It is an experience that would otherwise never exist. And is as extraordinary and wild as its namesake.

Tasting notes: COMPLEX \& HERBAL Earthy and layered with notes of fresh herbs and a lingering spice. The Starbucks Roast - Each coffee requires a slightly different roast to reach its peak of aroma, acidity, body, and flavor. We classify our coffees in three roast profiles, so finding your favorite is easy."

Blonde - Medium - Dark (with a circle on the dark end of the scale)

"The story of Italian Roast:

This is Starbucks quintessential dark roast - expertly crafted to bring out sweetness and intensity. It showcases the precision and skill of our roasters, who created a coffee that's slightly darker than our Espresso Roast without the smoky edge of French Roast. A great cup of coffee, it has a depth of flavor that holds its own with cream and sugar.

Tasting Notes: ROASTY \& SWEET Intense with a rich, deep flavor and notes of caramelized sugar."

Blonde - Medium - Dark (with a circle on the dark end of the scale)

\section{Starbucks, Cleveland Circle, 12/3/17}

- Interviewer: What's your favorite drink here?

a. Uh, pretty basic, I just drink like the regular iced coffee usually.

- Interviewer: How are you taught to greet customers?

a. Um, so, when we go through like our training there's like a model that we follow that's inside all our aprons there's like Starbucks values to anticipate, connect, personalize, and owe that's like the standard pillars we're supposed to follow. So if a customer has a complaint we're supposed to be positive. Just you know like the usual style, friendly. The thing Starbucks does very well is especially for our regulars, especially early in the morning or late at night, we get to know them by like a first name basis. That's just another way we take like the personalization to another well.

- Interviewer: Are there things you are not allowed to say to customers?

a. Um, I mean besides like the obvious not cursing them out and stuff for the most part, uh, we tend to try to keep like a friendly relationship with any customer even if they're difficult. Even with 
customers who like they're demanding or don't like something, again like it's the principle of trying to assume positive intent. We always have to assume positive intent and make it right. We always like to have customers leave happy.

- Interviewer: If/when customers become upset with you, how are you supposed to deal with that and what are they usually upset about?

a. Um, more often they're not, 9 times out of 10 it's a drink that's not made completely or they're waiting for food or drink or something especially when it's busy. Especially for problems that's like corporate issues we're supposed to defer them to upper management. Like, sorry, couldn't do xyz, offer a $4 \$$ gift card and tell them they can bring this to corporate. Like, if they're waiting for something we can try to speed up the process, but you know, if there's a line out the door (shrugs). Like the old adage that the customer is always right, Starbucks really agrees with that and I do too, to an extent.

- Interviewer: What's your dark roast like?

a. Um, which one in particular?

- Interviewer: No idea, I'm just trying to compare.

a. We usually rotate the different dark roasts, especially during the seasons. Right now, we have like the Christmas espresso roast which changes year to year but the thing they always have in common is they have an aged Sumatra, which adds like an earthy favor. This year there's much less than last year but it still has a like a smoky, sweet spicy taste. We also rotate through our core dark roasts which is like the Sumatra, French roast, Komodo dragon each one has a different characteristic especially based on the region they're harvested from. Like the Komodo dragon has a specific region, so they're just forming different areas where the coffee is harvested from. Like Asia, Pacific, Latin America's a big one too, there's another one I can't remember too. But each climate has like a different characteristic. But then it also depends on like who's tasting the coffee too. Similar to wine, you can pick up on different notes as well.

\section{Dunkin Donuts on Commonwealth Avenue across from St. Ignatius, 11/29/17}

- Interviewer: What's your favorite drink here?

a. Barista: Caramel swirl cream iced coffee.

Interviewer: What is that exactly?

a. Barista: It's an iced coffee with cream and caramel swirl.

- Interviewer: How are you taught to greet customers?

a. Barista: Smile, look people in the eye and ask them what they want. We're really trained through in person training and then online modules.

- Interviewer: Are there things you are not allowed to say to customers? (barista shakes head) Or is it more of like a style?

a. Barista: Just a courteousness, respectfulness

- Interviewer: If/when customers become upset with you, how are you supposed to deal with that and what are they usually upset about?

a. Barista: If we don't have a product they like. Then we try to suggest an alternative. And compliment them.

- Interviewer: What's the difference between a latte and a cappuccino?

a. Barista: Foam. A cappuccino has foam in it. They're both warmed milk.

Note: Sadly, I did not decide to ask about the dark roast until after this interview, as a further attempt to solicit coffee-related jargon and brand specific description.

\section{Dunkin Donuts, Cleveland Circle, 12/3/17}

- Interviewer: What's your favorite drink here?

a. Barista: Iced coffee. Just plain.

- Interviewer: How are you taught to greet customers?

a. Barista: With a smile, tell them to have a nice day, try to get them back.

- Interviewer: Are there things you are not allowed to say to customers?

a. Barista: (Thinks for a minute) well what do you mean by that?

b. Interviewer: Like, if there are phrases or words you're not supposed to say? 
c. Barista: No.

- Interviewer: If/when customers become upset with you, how are you supposed to deal with that and what are they usually upset about?

a. Barista: Well, the supervisor will deal with that, we'll grab her, let her know. We had a customer here and I would just grab her and she would take care of it. I would be as polite as possible and I would just walk away.

- Interviewer: What's your dark roast like?

a. Barista: I don't know, I don't normally drink it.

- Interviewer: Okay, that's it, thank you.

a. Barista: Ok sweetheart have a nice day.

Dunkin Donuts, Commonwealth Avenue across from St. Ignatius, 12/9/17

To compensate for my missing question, I merely asked about the dark roast before ordering.

- Interviewer: What's your dark roast like?

- Barista: Umm, I don't know. I've never had it. Do you want hot or iced? 
